\title{
Correction to: Flood hazard assessment and mapping of River Swat using HEC-RAS 2D model and high-resolution 12-m TanDEM-X DEM (WorldDEM)
}

\author{
Muhammad Farooq $^{1,2}$ (D) $\cdot$ Muhammad Shafique ${ }^{1} \cdot$ Muhammad Shahzad Khattak $^{3}$
}

Published online: 24 July 2019

(c) Springer Nature B.V. 2019

\section{Correction to: Natural Hazards https://doi.org/10.1007/s11069-019-03638-9}

The original article was updated and corrected due to numbering errors in Figure 8's subfigures and the placement of some of the article's other figures. Additional corrections were also made to the captioning of figures (Figure 9). This correction stands support the corrections made to the original article. The original article has been corrected.

Publisher's Note Springer Nature remains neutral with regard to jurisdictional claims in published maps and institutional affiliations.

The original article can be found online at https://doi.org/10.1007/s11069-019-03638-9.

Muhammad Farooq

alfarooq74@yahoo.com

1 National Center of Excellence in Geology, University of Peshawar, Peshawar, Pakistan

2 Pakistan Space and Upper Atmosphere Research Commission (SUPARCO), Islamabad Highway, Islamabad, Pakistan

3 Department of Agricultural Engineering, University of Engineering and Technology, Peshawar, Pakistan 